\title{
Psychiatric morbidity and illness behaviour in female neurological in-patients
}

\author{
RICHARD METCALFE, * DAVID FIRTH, $\dagger$ STEVEN POLLOCK, * FRANCIS CREED† \\ From the University Departments of Neurology, ${ }^{*}$ and Psychiatry, $\dagger$ Manchester Royal Infirmary, Manchester
}

SUMMARY Ninety three female neurological in-patients were assessed in a collaborative neurological and psychiatric study. An overall prevalence of definite psychiatric disorder of $34 \%$ was found, depression being the most common diagnosis. Psychiatric morbidity was most common when the neurologist felt that the presentation could not be explained by a neurological disorder. The majority of such patients had symptoms which could be explained by the psychiatric disorder but a substantial number could not be given a definite diagnosis. The General Health Questionnaire was not found to be a useful screening instrument in this setting.

The relationship between neurological and psychiatric illness is complex, partly because of the many ways in which these disorders interact ${ }^{12}$ but also because of very real semantic problems which arise in an area of clinical practice where illness and disease are difficult to define. Any systematic approach to the relationship must therefore start with a clear definition of terms (and a recognition of their limitations).

The term "psychiatric illness" has been applied in some previous studies only to those patients whose symptoms do not have an organic basis; the prevalence of such illness has been recorded in two studies of neurological out-patients as $30 \%$ and $13 \%$ respectively. ${ }^{34} \mathrm{~A}$ recent study of in-patients on our unit also included patients with psychiatric illness secondary to organic disease; the overall prevalence of psychiatric morbidity was estimated at $36 \%{ }^{5}$ and appeared to be similar for those with and without organic disease. This figure was lower than some surveys which have relied solely on self-report questionnaires to diagnose psychiatric illness. ${ }^{46}$ Thus a clear definition of psychiatric illness is required to measure accurately its prevalence.

The term "functional", "psychological" or "hysterical" are often used to describe the complaints of the numerous patients who are referred for a neurologist's opinion but who do not have detectable organic disease. $^{7-9}$ Many physicians regard these terms as synonymous with psychiatric illness, an assumption

Address for reprint requests: Dr $R$ Metcalfe, Department of Neurology, Manchester Royal Infirmary, Manchester M13 9WL, UK.

Received 19 January 1988 and in revised form 1 July 1988. Accepted 1 July 1988 which presumably indicates that psychiatric treatment would relieve the symptom. In fact only a proportion of patients who do not have an organic basis for their symptoms have psychiatric illness diagnosed according to research criteria. ${ }^{59}$

The term "illness behaviour" has been introduced to describe the excessive concern with bodily symptoms and inappropriate treatment-seeking observed in patients who are apparently motivated by fear of severe disease or by the potential rewards of the sick role. But the relationship between such behaviours and specific psychiatric diagnoses is not clear, ${ }^{10}$ and the nature of any underlying psychological disturbance must be identified in such patients if appropriate treatment is to be instituted.

For the purposes of the present paper patients who did not have organic disease will be termed "nonorganic" whereas the term "psychiatric disorder" will be used to denote the presence of sufficiently numerous and severe psychiatric symptoms to merit a diagnosis according to research criteria. Such a diagnosis was only made after an interview with a psychiatrist since a high score on a questionnaire alone does not necessarily indicate the presence of a psychiatric disorder. ${ }^{411}$

The first aim of the present study was to measure the prevalence of psychiatric illness in patients regarded by one neurologist as exhibiting non-organic symptoms (using those with organic illness as a comparison group). Secondly, we aimed to determine for each patient whether the psychiatric disorder played a part in causing the symptom presented to the neurologist (that is, would psychiatric treatment be expected to relieve the presenting symptom?). Thirdly, we tried to assess abnormal illness behaviour to see to what extent 
this was present in the patients with non-organic complaints. Such abnormal illness behaviour had been demonstrated among patients with hysteria referred to a psychiatrist, ${ }^{12}$ but its prevalence and severity among unselected patients in a neurological unit has not previously been assessed.

\section{Method}

Over a 3 month period 98 consecutive admissions to a 13 bed female investigation unit were invited to co-operate in the study. The study was performed on females only because they have a higher prevalence of both psychiatric illness ${ }^{57}$ and non-organic complaints' so this would maximise the chance of us being able to study the relationship between the two. Each patient was asked by the neurologist (SP) to complete a number of questionnaires. Permission was also sought for a later interview by the psychiatrist working on the ward (DF). The neurologist and psychiatrist then proceeded to make their assessments independently.

\section{Neurological assessment}

Following his initial assessment the neurologist completed a form listing the details of the presenting symptoms and his clinical opinion as to whether these represented underlying organic disease. His opinion was recorded graphically on a visual analogue scale (a $10 \mathrm{~cm}$ line), the two extremes representing symptoms either entirely explained or entirely unexplained by neurological disorder. This procedure was repeated at the time of discharge when the results of investigations, but not the psychiatric assessment, were available.

Using the neurologist's final mark on the visual analogue scale, the subjects were later divided into three groups.

Group 1 (within $10 \mathrm{mms}$ of the "organic" end of the line) represented patients whose symptoms were thought by the neurologist to be entirely explicable in terms of neurological disorder.

Group 2 (11-89 mms on the line) included those patients who either had symptoms which could be explained by dual processes (such as multiple sclerosis and depression) or who had symptoms which the neurologist doubted could be wholly explained by the organic disease that was recognised (such as non-specific symptoms in a patient with epilepsy).

Group 3 (90-100 mms on the line) were patients whose symptoms were not thought to represent organic disease of the nervous system.

In addition a discharge diagnosis was made and the presence of family, financial or legal factors which might be relevant were noted. The latter were recorded principally to see if any social problems were recognised by the neurologist; no formal scale was used.

\section{Psychiatric assessment}

During the first two days of admission the patients completed the General Health Questionnaire (28 items) (GHQ) ${ }^{13}$ and the Illness Behaviour Questionnaire (IBQ). ${ }^{14}$ A formal psychiatric assessment was performed using the Clinical Interview Schedule (CIS), ${ }^{15}$ if the GHQ score was over 5 or there was a specific request from the neurologist. The patient was given a psychiatric diagnosis if there were sufficient symptoms recorded on the CIS and an ICD diagnosis was merited (in practice all but three of the patients given such a diagnosis had a weighted CIS score of over 20).

At a later meeting of all the authors the details of neurological and psychiatric findings were examined with the aim of reaching a consensus decision about the cause or causes of the patient's symptoms. In particular the psychiatrist (FC) was required to decide to what extent the psychiatric diagnosis, if any, provided an explanation for the patient's symptoms.

Statistical comparison of differences between groups were made using chi square, Mann Whitney $U$ tests or KruskalWallis analysis of variance as appropriate.

\section{Results}

Ninety three patients took part in the study. Five were excluded, two refusing to take part, one being too unwell (as a result of a cerebral tumour) and in two cases the duration of in-patient stay was too brief. The neurological diagnoses of symptom groups were as follows: spondylosis, cerebrovascular disease (13 patients each diagnosis), multiple sclerosis, epilepsy, headache (12 patients each), dizziness (7), polysymptomatic (4) motor neuron disease, myasthenia (3 each) myotonica dystrophica (2), hysteria (1), miscellaneous (15).

Following his clinical interview, the psychiatrist diagnosed psychiatric illness in $32(34 \%)$ of patients. Eighteen patients had depression, seven a combination of anxiety and depression and two had an anxiety state. Two patients were psychotic, and one patient each was diagnosed as having hypomania, conversion hysteria and alcohol abuse. For brevity the term "affective" will be used hereafter to refer to the 28 patients with depression, anxiety and hypomania but excluding psychosis, hysteria and alcohol abuse. The term "affective treated" will refer to those 14 patients whose disorder was regarded as sufficiently severe to commence specific treatment (usually with antidepressants) while on the ward.

Table 1 shows the distribution of psychiatric disorder, median GHQ scores and life problems amongst these groups. It can be seen that a much higher proportion of Group 3 patients have a definite psychiatric disorder and the majority of these were severe enough to warrant immediate treatment.

Table 1 Psychiatric disorder and neurological groups

\begin{tabular}{|c|c|c|c|}
\hline & $\begin{array}{l}\text { Group 1 } \\
\text { Organic } \\
(n=54)\end{array}$ & $\begin{array}{l}\text { Group } 2 \\
\text { Uncertain } \\
(n=22)\end{array}$ & $\begin{array}{l}\text { Group } 3 \\
\text { Non-organic } \\
(n=17)\end{array}$ \\
\hline $\begin{array}{l}\text { Total affective } \\
\text { Treated affective }\end{array}$ & $\begin{array}{l}6 \\
0\end{array}$ & $\begin{array}{r}10 \\
5\end{array}$ & $\begin{array}{r}12 \\
9\end{array}$ \\
\hline $\begin{array}{l}(0-28) \\
\text { Median CIS } \\
\text { Life problems }\end{array}$ & $\begin{array}{r}7(0-20) \\
13(1-27) \\
3\end{array}$ & $\begin{array}{l}12 \cdot 5(0-26) \\
25(8-51) \\
9\end{array}$ & $\begin{array}{l}12(0-24) \\
30(7-50) \\
11\end{array}$ \\
\hline
\end{tabular}


Table 2 Psychiatric explanation for symptoms

\begin{tabular}{llll}
\hline & $\begin{array}{l}\text { Group 1 } \\
\text { Organic } \\
(n=54)\end{array}$ & $\begin{array}{l}\text { Group 2 } \\
\text { Uncertain } \\
(n=22)\end{array}$ & $\begin{array}{l}\text { Group 3 } \\
\text { Non-organic } \\
(n=17)\end{array}$ \\
\hline $\begin{array}{l}\text { Complete } \\
\text { Partial }\end{array}$ & 0 & 2 & $9(\mathrm{P}, \mathrm{H})$ \\
$\begin{array}{l}\text { Not at all } \\
\text { No psychiatric } \\
\text { illness }\end{array}$ & 6 & $8(\mathrm{P})$ & 1 \\
\hline $\mathrm{P}=$ Psychosis & 47 & 11 & 1 \\
\hline
\end{tabular}

$\mathbf{P}=$ Psychosis, $\mathbf{A}=$ Alcohol, $\mathrm{H}=$ Hysteria.

Table 2 demonstrates the extent to which the psychiatric diagnosis provided an explanation for the patient's symptoms. It can be seen that the psychiatric disorder played no part in causing the symptoms in Group 1 patients but provided a full explanation in over half of Group 3. This still left eight patients in this group in whom psychiatric disorder could not totally explain the symptoms. In group 2 the symptoms presented to the neurologist were rarely considered explicable solely in terms of psychiatric disorder.

Analysis of the IBQ scores revealed significant differences between the groups in three subscales using the non-parametric Krusker-Wallis test (table 3). Group 3 patients were distinguished by their pronounced somatic complaints (General Hypochondiasis scale). Conviction of severe disease and failure to be reassured by normal investigations (Disease Conviction scale) were found in both groups 2 and 3. As previous results have shown, these groups have a higher level of affective disorder than group 1.

The presenting neurological symptoms were heterogeneous so it was impossible to determine whether any were especially likely to indicate psychiatric disorder. However, we found no difference between patients in whom pain was a prominent presenting complain and the rest but those individuals with more than two complaints were much more likely to have a definite psychiatric diagnosis (table 4).

Finally, we subdivided the 28 patients with affective

Table $3 \quad I B Q$ scale scores

\begin{tabular}{lllll}
\hline & \multicolumn{2}{l}{ Median scale values } & \\
\cline { 2 - 4 } & $\begin{array}{l}\text { Group 1 } \\
\text { Organic } \\
(n=54)\end{array}$ & $\begin{array}{l}\text { Group 2 } \\
\text { Uncertain } \\
(n=22)\end{array}$ & $\begin{array}{l}\text { Group 3 } \\
\text { Non-organic } \\
(n=17)\end{array}$ & \\
\hline Scale & 0.5 & 1 & 5 & $\mathrm{p}<0.001$ \\
\hline $\begin{array}{l}\text { General } \\
\text { hypochon- } \\
\text { driasis } \\
(0-9)\end{array}$ & 2 & 3 & 4 & $\mathrm{p}<0.05$ \\
$\begin{array}{c}\text { Disease } \\
\text { conviction } \\
(0-6)\end{array}$ & 2 & 2 & 3 & $\mathrm{p}<0.05$ \\
$\begin{array}{c}\text { Affective } \\
\text { disturbance } \\
(0-4)\end{array}$ & 1 & & & \\
\hline
\end{tabular}

Table 4 Psychiatric disorder and number of symptoms

\begin{tabular}{|c|c|c|c|}
\hline \multirow[b]{2}{*}{ Complaints } & \multicolumn{2}{|c|}{ Psychiatric diagnosis } & \multirow[b]{2}{*}{ Total } \\
\hline & Case & Not case & \\
\hline $\begin{array}{l}1 \text { or } 2 \\
3 \text { or more } \\
\text { Total }\end{array}$ & $\begin{array}{r}24 \\
8 \\
32\end{array}$ & $\begin{array}{r}58 \\
3 \\
61\end{array}$ & $\begin{array}{l}82 \\
11 \\
93\end{array}$ \\
\hline
\end{tabular}

disorder according to clinical severity of psychiatric illness. This was performed on a clinical basis by the neurologists and psychiatrists in discussion and not according to the Clinical Interview Schedule Score. Group A comprised those with no affective disorder, Group B had mild and untreated affective symptoms and Group $C$ had more severe affective symptoms for which immediate treatment was initiated. The GHQ scores for these groups are shown in table 5. It can be seen that the GHQ scores did not provide a reliable guide to the presence of affective disorder since using the cut-off score of 11/12 recommended by Goldberg ${ }^{16}$ for this population, one quarter of the non-morbid group (Group A) would be false positives, half the mild affective group and even one quarter of the relatively severe treated group would be missed.

\section{Discussion}

This study has found that the overall prevalence of psychiatric disorder among female neurological inpatients is similar to that in the other general medical settings. ${ }^{17}$ It is important to note that this result arose from administration of a standardised psychiatric interview and not from a self-administered questionnaire as has been done in some previous studies ${ }^{46}$; it is close to the result of an earlier study at the same unit. ${ }^{5}$ The practical importance is that half of these patients warranted the initiation of treatment for their psychiatric disorder whilst on the ward.

Our results indicate that the clinician could not rely on the use of the General Health Questionnaire to indicate which patients have psychiatric illness, since some patients in the affective groups recorded low scores on the GHQ. This was also the finding of a previous study on neurological outpatients ${ }^{4}$ and has also recently been confirmed by the author of the questionnaire. ${ }^{16}$ Currently available questionnaires

Table $5 \mathrm{GHQ}$ scores in affective disorder groups

\begin{tabular}{llll}
\hline & $\begin{array}{l}\text { Group A } \\
\text { No disorder } \\
(n=61)\end{array}$ & $\begin{array}{l}\text { Group B } \\
\text { Mild affective } \\
(n=14)\end{array}$ & $\begin{array}{l}\text { Group C } \\
\text { Treated affective } \\
(n=14)\end{array}$ \\
\hline $\begin{array}{l}\text { GHQ total } \\
\text { Median }\end{array}$ & $5 \cdot 5$ & 12 & $17 \cdot 5$ \\
$\begin{array}{l}\text { Quartiles } \\
\text { Range }\end{array}$ & $2-11$ & $5-18$ & $\begin{array}{l}10-24 \\
4-25\end{array}$ \\
\hline
\end{tabular}


cannot accurately detect psychiatric illness in individual cases and there is clearly no easy alternative to a carefully taken history. In this context, we confirm the validity of the feature that has always alerted the physician to the presence of psychiatric illness, namely multiple complaints.

In line with previous studies we have found that over half of the patients whose symptoms were considered non-organic by the neurologist were suffering from an affective disorder. ${ }^{1218}$ But unlike previous studies we have studied the relationship between psychiatric disorder and the presenting somatic symptoms. The psychiatrists (FHC,DF) were confident that in many of these patients the symptoms were explicable in terms of defined psychiatric diagnosis and thus it was reasonable to pursue psychiatric treatment with the expectation that this should relieve the symptoms. The remainder of the group with non-organic complaints remain undiagnosed. It is not appropriate to designate them as "psychiatric" on the grounds that no organic cause for their symptoms has been discovered. Rather they should be managed by a doctor who can keep an open mind as only time will tell whether they are eventually diagnosed as having a psychiatric illness, a neurological disorder or neither. ${ }^{19}$

Thus the categories of "non-organic" and "psychiatric" illness are not synonymous, though they do overlap. Over half of those who had psychiatric illness also had organic neurological disease. The neurological symptoms in these patients were either unaffected by the coexisting psychiatric disorder (group 1) or exaggerated (group 2) or they had additional symptoms which caused diagnostic difficulty (also group 2).

The patients in group 3 were probably regarded as having "non-organic" symptoms primarily because of the nature of their presenting symptoms but we cannot rule out the possibility that their hypochondriacal attitude played a part in this decision. Such an attitude was pronounced as their very high scores on the Illness Behaviour Hypochondriasis and Disease Conviction scales testify. Nearly half of the patients in group 3 scored more than 3 on the hypochondriasis scale compared with $19 \%$ of general hospital patients and $30 \%$ of pain clinic patients. ${ }^{20}$ The median score was also a great deal higher than the patients with nonorganic symptoms referred by neurologists to a psychiatrist $^{12}$; such patients are a selected group who agree to such a referral.

The present sample included many patients who would bitterly resent formal referral to a psychiatrist. Such patients present neurologists with a difficult management problem; their illness behaviour is unlikely to be modified unless they can acknowledge the influence of psychological, social and economic factors in the causation of their difficulties; these must be tackled without alienating the patient. Like Lipowski and Kiriakos ${ }^{2}$ we believe co-operative management by neurologist and psychiatrist on a ward which operates without bias and accepts the validity of all symptoms, whether they are "organic" or "functional" provides the best therapeutic environment for such patients.

\section{References}

1 Lishman WA. Organic Psychiatry. Oxford: Blackwell, 1978.

2 Lipowski ZJ, Kiriakos RZ. Borderlands between neurology and psychiatry. Psychiatry in Medicine 1972;3:131-47.

3 Kirk C, Saunders M. Primary psychiatric illness in a neurological out-patients department in North-East England. J Psychosom Res 1977;21:1-5.

4 Kirk C, Saunders M. Psychiatric illness in a neurological out-patients department in North-East England. Use of the General Health Questionnaire in the prospective study of neurological out-patients. Acta Psychiat Scand 1979;60:427-37.

5 Bridges K, Goldberg DP. Psychiatric illness in in-patients with neurological disorders: patients' views on discussion of emotional problems with neurologists. $\mathrm{Br} \mathrm{Med} \mathrm{J}$ 1984;289:656-8.

6 De Paulo JR, Folstein MF, Gordon B. Psychiatric screening in a neurological ward. Psychol Med 1980;10:125-32.

7 Kirk C, Saunders M. Primary psychiatric illness in a neurological out-patients department in North-East England. An analysis of symptomatology. Acta Psychiat Scand 1977;56:294-302.

8 Marsden CD. What should neurologists do? J Neurol Neurosurg Psychiatry 1981;44:1059-60.

9 Fitzpatrick R, Hopkins A. Referrals to neurologists for headaches not due to structural disease. J Neurol Neurosurg Psychiatry 1981;44:1061-7.

10 Marsden CD. Hysteria - a neurologist's view. Psychol Med 1986;16:277-88.

11 Bridges K, Goldberg DP. Validation of the GHQ-28 and the use of the MMSE in neurological in-patients. $B r J$ Psychiatry 1986;148:548-53.

12 Trimble $\mathrm{M}$, Wilson-Barnett J. An investigation of hysteria using the Illness Behaviour Questionnaire. Br J Psychiatry 1985;146:601-8.

13 Goldberg DPG. Manual of the General Health Questionnaire. Windsor: NFER, 1978.

14 Pilowsky I, Murrell TGC, Gordon A. The development of a screening method for abnormal illness behaviour. $J$ Psychosom Res 1979;23:203-7.

15 Goldberg DP, Cooper B, Eastwood MR, Kedward HB, Shepherd M. A standardised psychiatric interview for use in community surveys. Br J Prev Soc Med 1970;24:18-23.

16 Goldberg DPG. Identifying psychiatric illness among general medical patients. Br Med J 1986;293:1188-9.

17 Mayou R, Hawton K. Psychiatric disorder in the general hospital. Br J Psychiatry 1986;149:172-81.

18 Roy A. Hysteria. J Psychosom Res 1980;24:53-6.

19 Slater E, Glithero E. A follow-up of patients diagnosed as suffering from hysteria. J Psychosom Res 1965;9:9-13.

20 Pilowsky I, Spence ND. Manual for the Illness Behaviour Questionnaire. Adelaide: Adelaide University Press, 1981. 